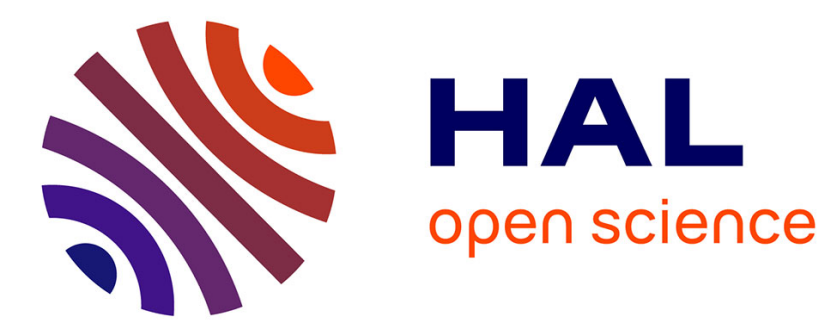

\title{
Pressure rolling contact: steady state flow analysis and comparison with experimental data
}

\author{
Eric Hanus, Habibou Maitournam, Ky Dang Van
}

\section{To cite this version:}

Eric Hanus, Habibou Maitournam, Ky Dang Van. Pressure rolling contact: steady state flow analysis and comparison with experimental data. International Journal of Solids and Structures, 1996, 33, pp.3739-3753. hal-00111520

\section{HAL Id: hal-00111520 \\ https://hal.science/hal-00111520}

Submitted on 4 Sep 2019

HAL is a multi-disciplinary open access archive for the deposit and dissemination of scientific research documents, whether they are published or not. The documents may come from teaching and research institutions in France or abroad, or from public or private research centers.
L'archive ouverte pluridisciplinaire HAL, est destinée au dépôt et à la diffusion de documents scientifiques de niveau recherche, publiés ou non, émanant des établissements d'enseignement et de recherche français ou étrangers, des laboratoires publics ou privés. 


\title{
PRESSURE ROLLING CONTACT: STEADY STATE FLOW ANALYSIS AND COMPARISON WITH EXPERIMENTAL DATA
}

\author{
ERIC HANUS, HABIBOU MAITOURNAM and KY DANG VAN \\ Laboratoire de Mécanique des Solides, CNRS URA 317, Ecole Polytechnique, \\ 91128 Palaiseau Cedex, France
}

\begin{abstract}
In the present work the pressure rolling treatment has been modelled by a direct stationary method which gives the stabilized mechanical state after complete rolling. One important input to the model is the pressure distribution at the contact between the roller and the sample. Due to the conforming geometries of the bodies in contact it is found that the pressure distribution differs from the one calculated with the Hertz theory. The numerical outputs from the pressure rolling model have been compared to experimental data, i.e. the residual stresses measured by X-ray diffraction. A good agreement between experimental and numerical results is obtained for the penetration depth and the residual stress prof It is found that friction has a strong influence on the surface residual stress.
\end{abstract}

\section{INTRODUCTION}

First introduced in the railroad industry, pressure rolling is a mechanical surface treatment in which a load is applied by contact of a rotating tool-the roller-to a workpiece. According to the load intensity three applications for pressure rolling may be distinguished. At low load levels the treatment smooths down ruggedness thus enhancing the surface finish. To cover the whole sample surface, sliding motion can be coupled to rolling. Flavenot and $\mathrm{Lu}(1988)$ measured a ruggedness of $0.4 \mu \mathrm{m}$ after pressure rolling against $15.4 \mu \mathrm{m}$ after shot peening a stainless steel. At intermediate loads the smoothing effect can be used to improve the dimensional margins. In this connection tolerances lower than $0.02 \mathrm{~mm}$ can be achieved (Benamar et al., 1991). Finally, pressure rolling under large loads is a way to increase the fatigue strength of conventional materials (Brand et al., 1980; Mahnig, 1981) or even of recently developed metal matrix composites. A $30 \%$ improvement has been observed on a pressure rolled 2014+15\% SiC particles (Hanus and Ericsson, 1995a). As for shot peening the underlying mechanism is surface plastic deformation which generates compressive residual macrostresses and local work hardening.

Even though pressure rolling is well implanted in the mechanical industry, its use and development rely essentially on an empirical knowledge. One can nevertheless mention the work of Braham (1991) who proposed a numerical model based on the simplified analysis of inelastic structures (Zarka, 1980; Zarka et al., 1988). This very fast method which goes straight to the stabilized state is however approximate since the solution that one builds under the maximum applied load with purely elastic calculations, is not guaranteed to be the exact one. It is therefore of interest to model efficiently the complete deformation process associated with this mechanical treatment.

This study on the pressure rolling treatment presents the numerical results obtained with the direct stationary method developed by Dang Van and Maitournam (1993) and compares the major outputs concerning the residual stresses with experimental data available for a particulate reinforced metal matrix composite (Hanus and Ericsson, 1995b). Special attention has been paid on parameters such as the pressure distribution at the contact and the friction. 


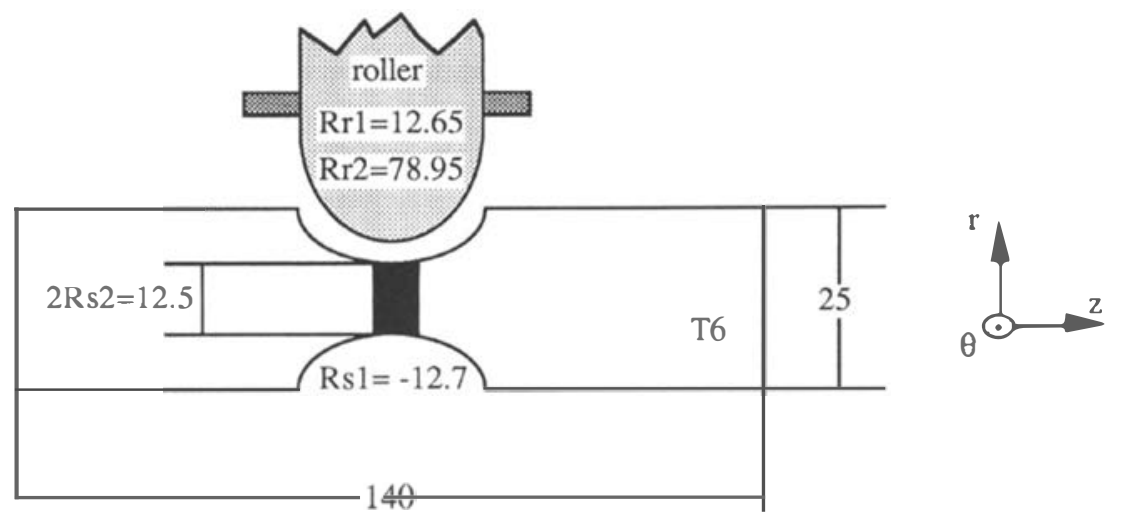

Fig. 1. The specimen and roller geometries (the rolling track is coloured in black). Distances in mm. Rolling occurs along the hoop direction.

\section{EXPERIMENTAL DETAILS}

The material under investigation is a 2014 aluminium alloy reinforced by 15.5 volume percent of silicon carbide particles. Details concerning the chemical composition of the alloy, the characteristics of the reinforcement phase and the microstructure have been reported in former studies (Hanus and Ericsson, 1995b; Hanus, 1993).

The geometries of the specimen and of the roller are presented in Fig. 1. The roller geometry was designed in order to match the sample groove. As a consequence the two radii of curvature $R r 1$ and $R s 1$ are in absolute value very close : 12.70 against $12.65 \mathrm{~mm}$.

The samples were heat treated to peak hardness prior to rolling under $9200 \mathrm{~N}$. The peak hardness conditions (T6) were a solution treatment of $2 \mathrm{hr}$ at $500^{\circ} \mathrm{C}$, subsequent water quenching and ageing for $14 \mathrm{hr}$ at $180^{\circ} \mathrm{C}$ (Hanus, 1993).

The rolling procedure is performed according to a specific loading history consisting typically of three cycles to reach the maximum applied load, ten cycles at stabilization and then unloading in three cycles. A specific lubricant is added while rolling, as recommended by the manufacturer Hegenscheidt. Concerning the friction coefficient between the hard steel roller and the composite sample no dynamic value was found in the literature. By analogy with the lubricated rolling contact of steel pieces, its value was fixed by default to 0.1 .

Figure 2 shows the macrostructure of a rolled specimen. As usual the rolled zone is brighter than the machined surface. From this photograph one also notices the presence of two whiter lines equally distant from the track center. These wear lines, already observed by Heathcote (1921) in unlubricated ball-bearing races, are lines of no slip.

The macrograph of Fig. 3 represents a cross section of a pressure rolled sample. To prevent any artefact the polishing was performed unidirectionally from the top to the bottom of the picture. It clearly shows the plastically deformed region induced by pressure rolling which is about 900 microns deep.

Rather curious is the surface mismatch at the right hand side of the track. Even though it is not seen on the left hand side this little step is observed on all the pressure rolled specimens, which suggests that local lateral plastic flow has occurred perpendicularly to the rolling track. Such a progressive extrusion attributed to local plastic ratchetting has already been reported with continuous sliding. Two ways in which the process can be driven may be identified:

- cyclic stressing of the soft surface by the stress concentrations which occur at the edges of a hard slider (Akagaki and Kato, 1987), and

- pummelling of the soft surface by the asperities of the hard surface (Kapoor and Johnson, 1994).

In the present case the pummelling of the ridges generated during machining-turning - by the asperities of the hard roller may explain the formation of the step. 


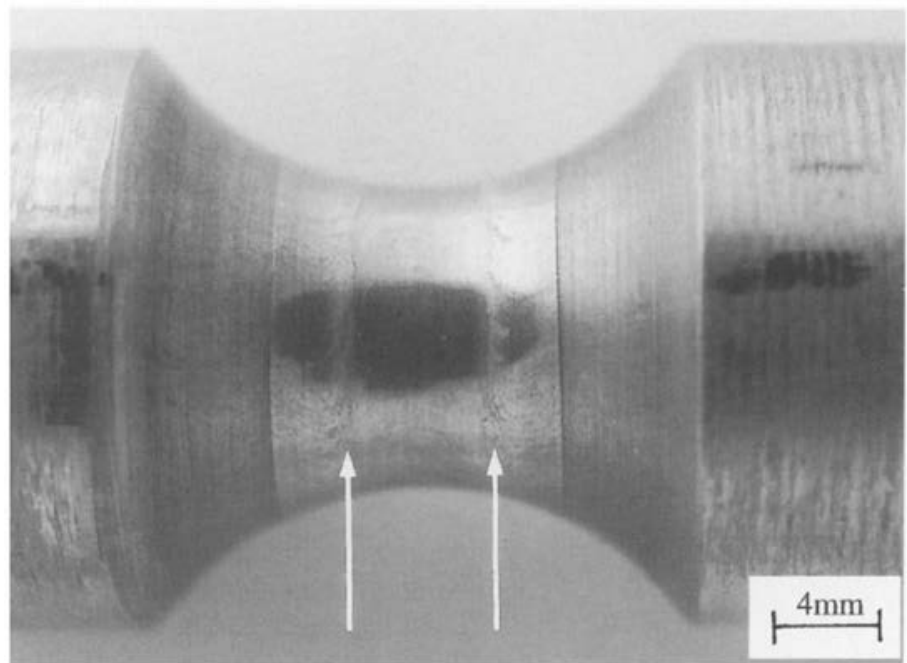

Fig. 2. Surface of the sample after pressure rolling. The arrows point towards the two wear lines. The dark ellipse is due to the lighting configuration and is therefore to be forgotten.

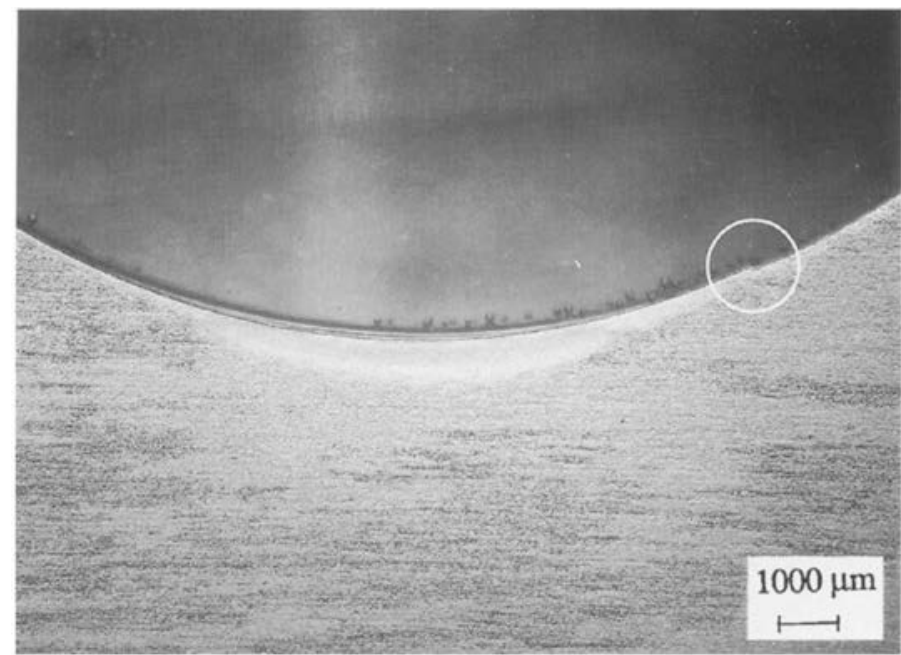

Fig. 3. Size of the plastically deformed zone generated by pressure rolling. The circular window displays the surface step. 
Table 1. Mechanical parameters derived from cyclic compressive testing. Young's modulus $E$, Poisson's ratio $v$, yield stress $\sigma_{e l}$ and tangent modulus $E_{t}$

\begin{tabular}{ccccc}
\hline Material & $E(\mathrm{GPa})$ & $v$ & $\sigma_{e l}(\mathrm{MPa})$ & $E_{t}(\mathrm{GPa})$ \\
\hline $2014+\mathrm{SiC}$ & 100.3 & 0.3 & 380 & 29.5 \\
\hline
\end{tabular}

Due to the large difference in coefficient of thermal expansion between the metallic matrix and the ceramic phase, tensile residual microstresses in the matrix of the composite are generated during heat treatment to T6. They induce a significant difference in mechanical properties observed between monotonic tension and monotonic compression: the $0.2 \%$ yield stress is $50 \mathrm{MPa}$ larger in compression than in tension (Persson et al., 1993). This dissymetry should not be forgotten when choosing the proper mechanical data. But pressure rolling is also a repeated rolling contact process, it is thus important to follow the evolution with cycling of the mechanical parameters. The cyclic stress-strain curve was therefore determined by using the multiple step testing, wherein the same sample is subjected to a series of alternating strains in blocks of increased magnitude. No significant cyclic hardening was observed in tension, but cyclic softening was measured in compression. By inspection of the hysteresis loop $(\sigma, \varepsilon)$ it was found that the hardening is of kinematic nature. The data used in the present study are those corresponding to cyclic compressive testing. They are shown in Table 1. Using the cyclic data is indeed of prime importance since with the direct stationary method which is described in the next section, one shall directly get the strain and stress states after the whole pressure rolling history.

\section{THEORY}

\subsection{The steady-state method}

The particularity of this approach is to analyse the rolling problem in an orthogonal reference frame $(r, \theta, z)$ associated with the moving load transmitted by the roller. Assuming constant angular velocity $\omega$ all the physical properties are no longer time dependent but position dependent along the rolling direction $\theta$ :

$$
\text { for any tensor } M, \frac{\mathrm{d} M}{\mathrm{~d} t}=-\omega \frac{\partial M}{\partial \theta}
$$

Under the further small strains hypothesis it is possible to derive all the equations of the evolution problem in elastoplasticity: equations of motion, boundary and initial conditions, constitutive laws and possible stabilized state (Dang Van and Maitournam, 1993). In practice the main difference with a classical method lies in the determination of the plastic strain rather than its rate and of the internal parameters such as hardening. For instance the plastic strain which is calculated from:

$$
\frac{\mathrm{d} \varepsilon^{p}}{\mathrm{~d} t}=\lambda \frac{\partial f}{\partial \sigma}
$$

can be rewritten with eqn (1):

$$
\frac{\mathrm{d} \varepsilon^{p}}{\mathrm{~d} \theta}=\lambda * \frac{\partial f}{\partial \sigma}
$$

which, after integration, leads to: 


$$
\varepsilon^{p}(r, \theta, z)=\int_{\theta}^{2 \pi}\left(\lambda * \frac{\partial f}{\partial \sigma}\right)(r, \xi, z) \mathrm{d} \xi+\varepsilon^{p}(r, 2 \pi, z)
$$

where $\lambda^{*}$ is given by the consistency condition:

$$
\lambda^{*}=\frac{\kappa}{h}\left\langle-\frac{\partial f}{\partial \sigma}: \sigma_{, \theta}\right\rangle
$$

in which $h$ is the hardening modulus, $f$ the function associated to the plasticity criterion, $\langle\cdot\rangle$ means the positive part, and $\kappa$ is defined according to :

$$
\kappa=1 \text { if } f=0 \quad \text { and } \quad \kappa=0 \text { if } f<0
$$

The assumption of a stabilized mechanical state for repeated rolling gives the complementary continuity equation:

$$
\int_{0}^{2 \pi} \varepsilon_{\theta \theta}^{p} \mathrm{~d} \theta=0
$$

This original approach is very different from the one proposed by Bhargava et al. (1985a, 1985b, 1988). In their study they used a finite element method with incremental translations of the loading. Their approach is obviously time consuming and rather cumbersome.

For computation the afore-mentioned equations are discretized over a finite mesh. The first step consists of determining the elastic response of the specimen to the loading. An initial strain field and its associated self-equilibrated stress field can be taken into account so that influence from prior treatments, for example quenching, may be introduced. If the plasticity criterion, e.g. von Mises criterion, is violated, projection of the stress field onto the elastic convex is performed. The solution one then gets is schematically represented in Fig. 4(a) (for the sake of clarity a two-dimensional representation has been chosen). If it is plastically admissible, the algorithm is stopped. Otherwise one may choose between two options:

-reiterate the projections until the plastic admissibility of the stress field is reached, or

—reinitialize the mechanical fields ahead of the loading and repeat that double loop: projection/initialisation until that the criterion of plasticity is satisfied.

The first case leads to the exact solution after one single pass of the roller which was proven to be unique (Dang Van and Maitournam, 1993). Following the second way, depicted in Fig. 4(b), gives directly the stabilized mechanical state after complete rolling. In the following all the calculations are using this so-called direct stationary method.

So far the problem of cyclically loaded structure has been reduced to a quasi-single pass of the roller. But it still remains three-dimensional due to the geometry of the contact. Using the development in Fourier series described by Zienkiewicz (1977) it is possible to further model the whole process by a succession of two-dimensional calculations (Maitournam and Dang Van, to be published).
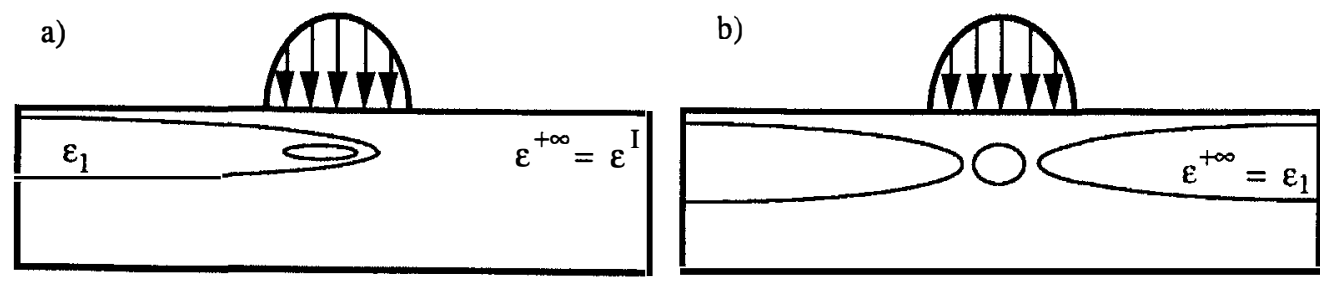

Fig. 4. Description of the single-pass algorithm (a) and direct algorithm (b). 


\subsection{The contact}

3.2.1. Pressure distribution. Regarding the contact a convenient assumption is to consider that it can correctly be described by the Hertz theory (Johnson, 1985; Hills et al., 1993). This theory gives indeed analytical expressions for the contact area and the pressure distribution which both are elliptical. It just requires the knowledge of the total applied force and the elastic constants of the two bodies in contact. To check its validity in the case of pressure rolling we need to go through all its assumptions which are:

(i) the surfaces are continuous and non conforming, i.e. the dimension of the contact is small compare to the radius of curvature,

(ii) each solid can be considered as an elastic half-space, and

(iii) the surfaces are frictionless.

As shown in Fig. 1 the surfaces of the specimen and the roller are locally quadratic and therefore the surfaces can be considered as continuous. Regarding the elastic character of the bodies, the hard steel roller does not undergo any plastic deformation during pressure rolling but of course the metal matrix composite does. However when modelling one's attention is just focused on the stabilized state. If this one is characterized by an elastic shakedown then the material response to the loading is entirely elastic and the assumption is validated. If the shakedown is plastic, i.e. the specimen response follows a closed plastic hysteresis loop, Barghava et al. (1985a) showed in the rolling case that the increase in contact area can be neglected even though the ratio of the Hertz maximum pressure to the shear yield stress is large $(\sim 5)$.

Although some restrictions may be relaxed, the one concerning the non-conforming half-space can not be overcome. Data from Fig. $1(R r l$ and $R s 1)$ clearly indicate that the contact exhibits an important conformity, i.e. the contact surface can not be assimilated to its tangent plane. It is thus necessary to look into more details at the effective pressure distribution applied to the specimen. The approach chosen here is to simulate with a finite element program the effective pressure distribution at the contact.

3.2.2. Tangential loading. As mentioned in the former section the roller imprint may be separated into three bands. In the outer regions microslip occurs forwards, i.e. the net tangential force applied to the specimen is opposite to the rolling direction, while in the central part microslip occurs backwards. This phenomenon is correlated to the close conformity of the contact area which is no longer plane but shares the transverse curvature of the roller and the sample. Surface points at a given longitudinal position $(z$-axis in Fig. 1) have different peripheral speeds depending on whether they belong to the roller or to the specimen, inducing thus microslip. Following Johnson (1985) one can analyse this particular situation by the strip theory illustrated in Fig. 5. Note that in the present study the pressure distribution and the contact area are no longer described by ellipses.

For each strip the Carter theory (Carter, 1926) is applied : a stick region at the leading edge, whose center is located at $x=-d$, is followed by a slip region at the trailing edge. The evolution of the stick region size is given by:

$$
d / a=\Gamma\left(\gamma^{2}-z^{2} / b^{2}\right)
$$

where $\gamma$ is determined optically and $\Gamma$ is the conformity factor equal to 22 for the present geometries (Johnson, 1985). Constants $a$ and $b$ are given by the finite element calculations.

\section{RESULTS AND DISCUSSION}

\subsection{The conforming contact}

To get an idea of the shape of the contact area, one can draw contours of equal distance between the two surfaces described in Fig. 1. In a cartesian frame centered on the middle of the groove, whose $z$-axis is parallel to the specimen axis and whose $x$-axis points towards the center of the roller, this distance, $D$, is given by: 


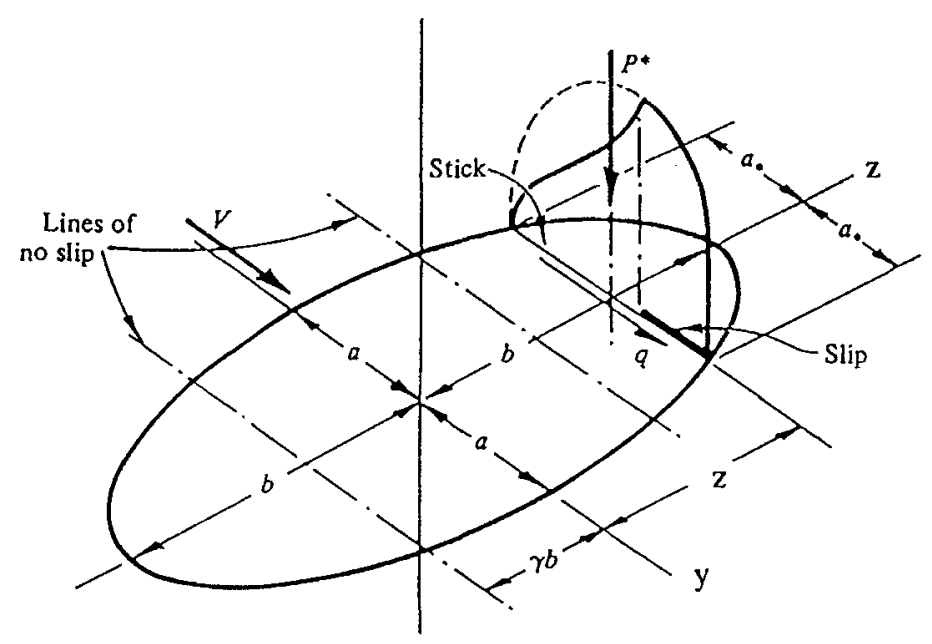

Fig. 5. Strip theory applied to a ball rolling in a conforming groove. Pure rolling takes place on two lines at $y= \pm \gamma b$ (Johnson, 1985).

$D=R s 2+R r 2-\left[\left(R r 2-R r 1+\left(R r 1^{2}-z^{2}\right)^{1 / 2}\right)^{2}-y^{2}\right]^{1 / 2}-[(R s 1+R s 2$

$$
\left.\left.-\left(R s 1^{2}-z^{2}\right)^{1 / 2}\right)^{2}-y^{2}\right]^{1 / 2}
$$

As shown in Fig. 6 the contact area is not elliptical as it would be a Hertzian contact but closer to an "eight form" especially when large displacements are involved.

As, during contact, the surfaces will deform it cannot be assumed that the shape will be the one given by Fig. 6 . Furthermore lacking any analytical analysis the problem was treated by a finite element model wherein the roller is described by a rigid body and the specimen by an homogeneous isotropic elastic body.

The calculations were performed using the Castem 2000 code developed by the Commissariat at l'Energie Atomique and run on Hewlett Packard work stations of $64 \mathrm{MB}$ random access memory. Since the roller was considered as rigid only the specimen geometry

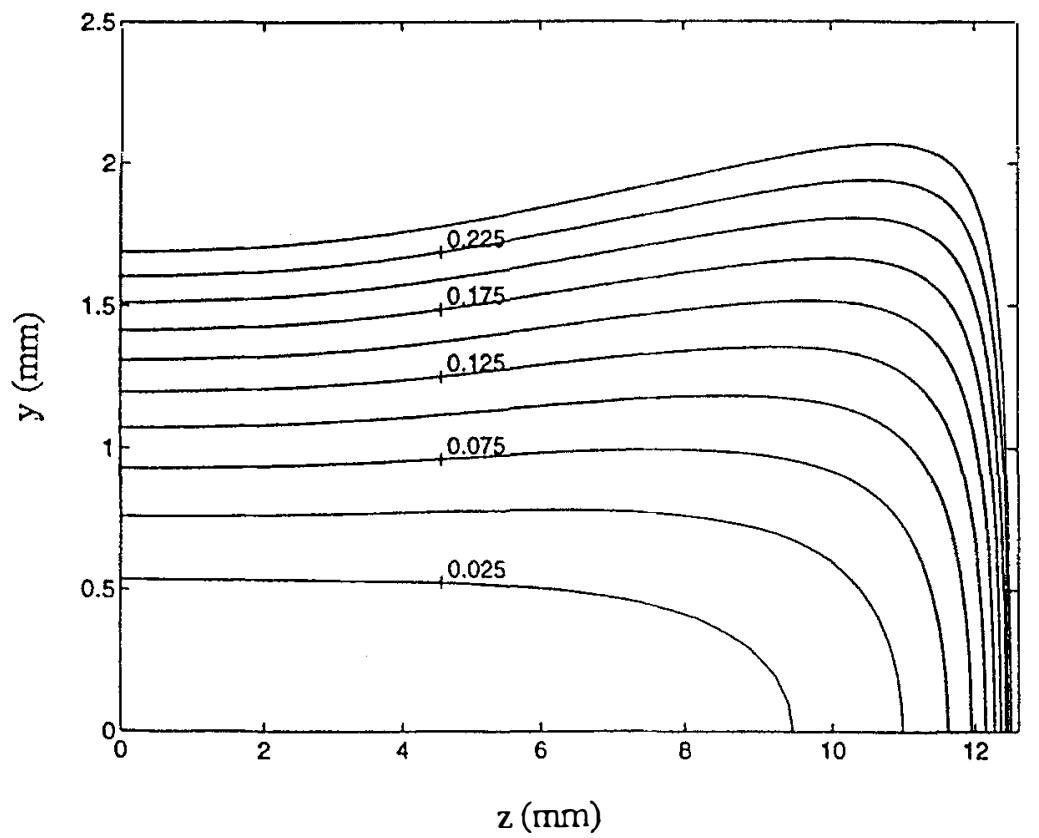

Fig. 6. Contours of the distance separating the specimen to the roller. Only one quadrant of the contact area is drawn $(0,0)$ is the center of the groove. Distance in $\mathrm{mm}$. 

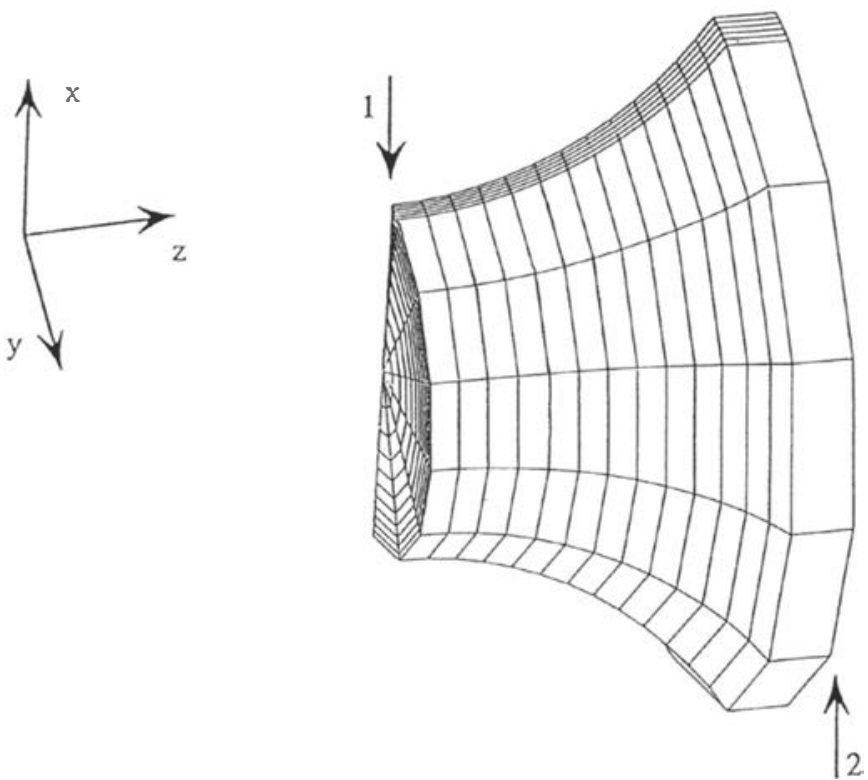

Fig. 7. Three-dimensional mesh of the groove. Arrow 1 points towards the point of first contact. Arrow 2 indicates where the displacement was blocked by the secondary roller.

was discretized. The three-dimensional mesh adopted in this section is represented in Fig. 7. Due to symmetry just one quarter of the sample needed to be examined. Further reduction could not be done because of boundary conditions : to sustain the load applied by the roller the specimen was blocked by two other small rollers placed at $\pm 120^{\circ}$ in the hoop direction on the sides of the specimen (out of the groove) so that bending was allowed. Nodes in both radial and orthoradial directions were concentrated close to the contact area. A crosssection consisting typically of 180 nodes was repeated 12 times in the hoop direction.

By prescribing the upper surface of the groove to be perpendicularly displaced, to a given extent, according to the roller surface geometry, one can calculate by integration of the stress tensor over the deformed area the total applied force. Depending on that value one modifies the displacement until the $9200 \mathrm{~N}$ load is reached. One can then determine the normal load $p_{n}$ on the surface, given by:

$$
p_{n}=(\sigma \cdot n) \cdot n
$$

where $\sigma$ is the stress tensor and $n$ the normal to the surface.

The results for the pressure (normal load) are presented in Fig. 8(a) and (b) while the equivalent stress on Von Mises is shown in Fig. 8(c). For comparison the pressure given by the Hertz theory is also plotted - the long axis of the contact ellipse is taken along the groove.

Even though a more refined mesh - only 2500 nodes are used in the present studywould have reduced the approximations made in the integration calculation of the global applied force, some useful comments may be drawn from Fig. 8 :

- the most striking feature is that the maximum in normal pressure is not located at the center of the groove, as predicted by the Hertz theory, but few millimeters outside;

- a decrease of $14 \%$ in the central pressure is also recorded ;

- the ratio of the maximum pressure to the shear strength is equal to 5 so that the stabilized state will be a plastic shakedown (Johnson, 1985), as confirmed by our calculations of Section 4.2 ;

- one can further notice that the dimensions of the contact ellipse given by the Hertz theory fit within $13 \%$ to those obtained by computation; 
(a)

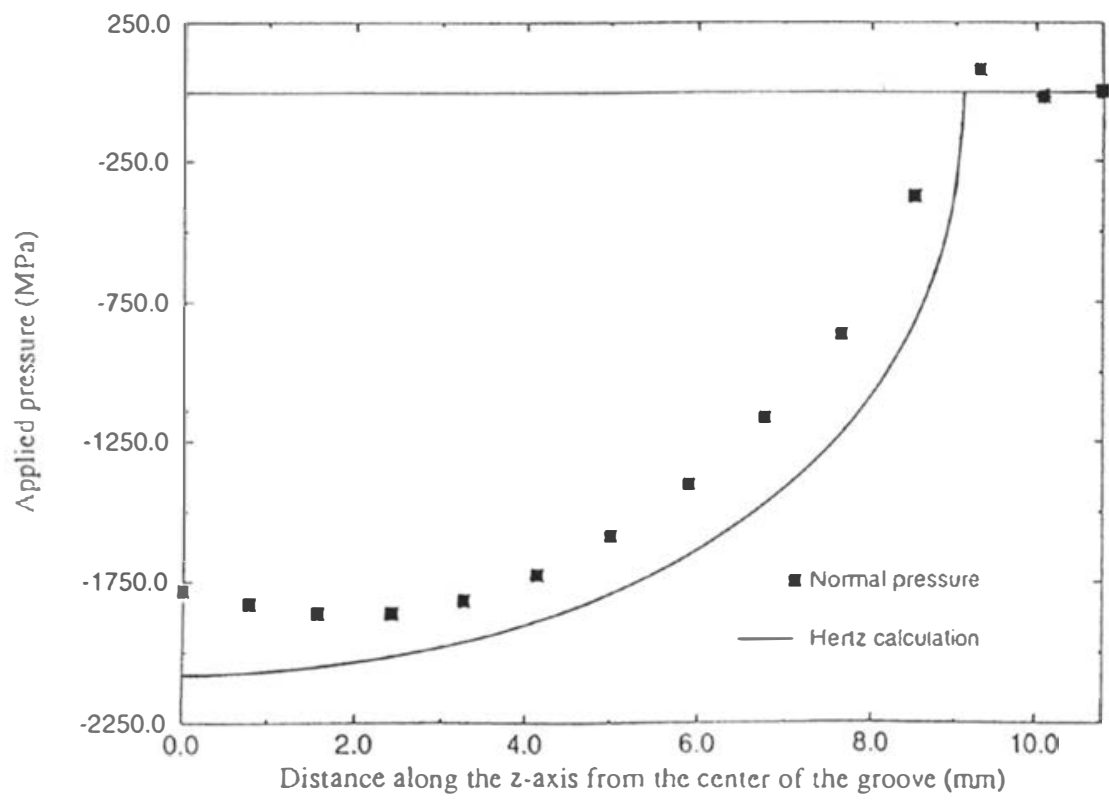

(b)

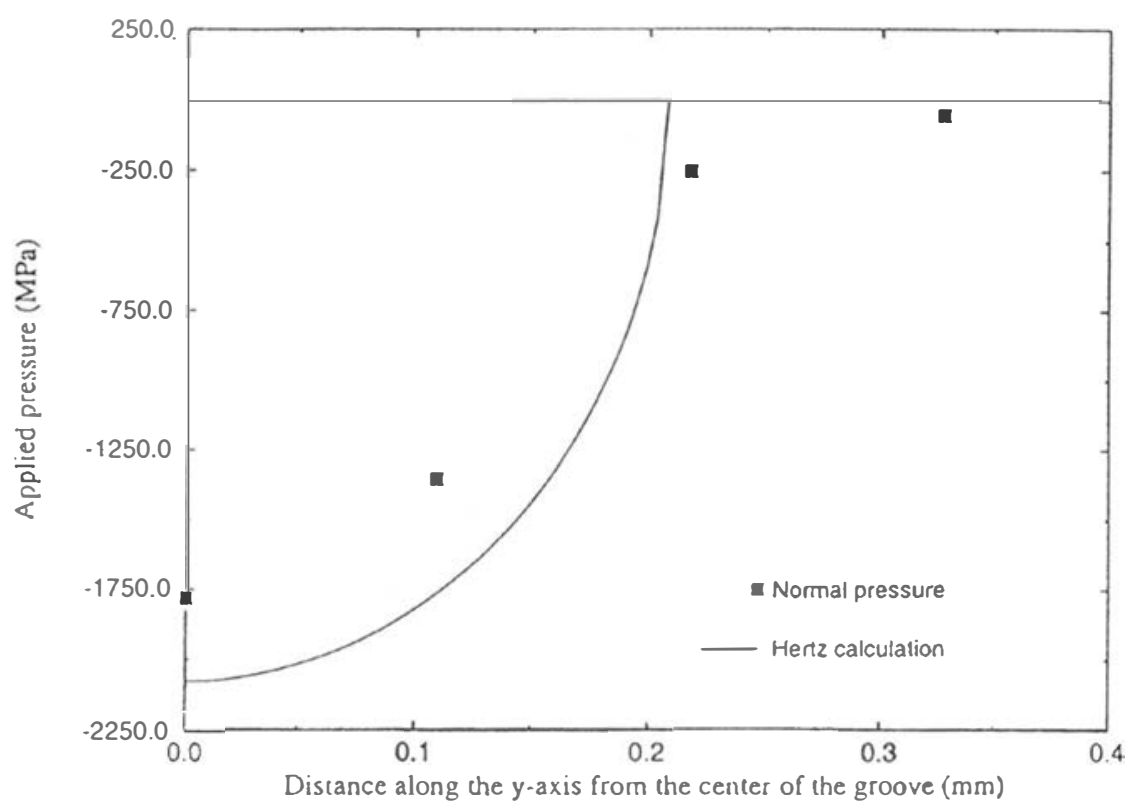

(c)

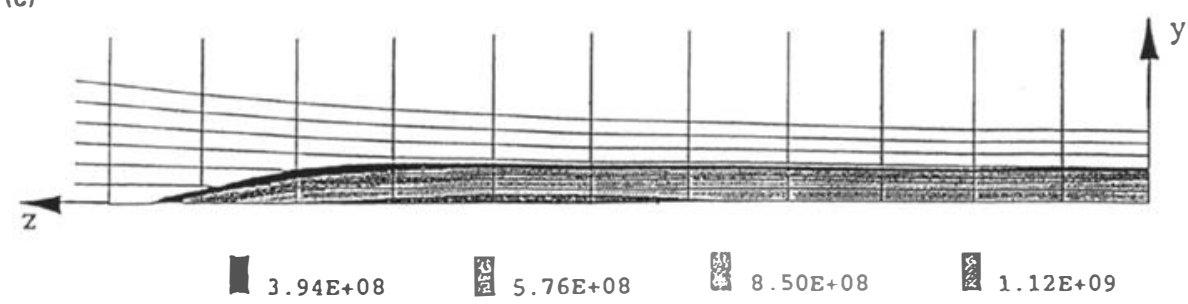

Fig. 8. Pressure distributions along the groove (a) and the transverse circle (b). Contours of the Von Mises stress $(\mathrm{Pa})$ at the contact zone (c). 
- as expected (cf Fig. 6) the contact area tends to be wider at the extremity of the long axis. This phenomenon would be more accentuated for larger applied loads since the conformity plays then a more pronounced role;

- of interest are also the variations of the Von Mises stress shown in Fig. 8c. Its maximum is located at the surface of the specimen away from the center of the groove. Could this maximum be one reason for the formation of the step observed in Fig. 2, a correct answer to this question still necessitates some more investigation. In the $(x, y)$ plane a local maximum in the equivalent stress occurs beneath the surface as it usually is in non-conforming Hertzian contact.

In the analysis presented above the influence of the elastic compliance is not taken into account and it would certainly be a non negligible factor. The elastic constants of the hard steel roller are indeed: $E=210 \mathrm{GPa}$ and $v=0.3$. The Hertz predictions give for the elastic/elastic contact a maximum pressure which is $24 \%$ lower than the one evaluated in the rigid/elastic case and contact ellipse dimensions $14 \%$ larger. It was deliberately chosen not to use the contact modulus $E_{c}$ in the precedent calculations since its definition $E_{\mathrm{c}}=\left(v_{1} / E_{1}+v_{2} / E_{2}\right)^{-1}$ is not guaranteed in the case of conforming contacts.

\subsection{Residual stresses}

The residual stresses were measured experimentally by X-ray diffraction in the two phases of the metal matrix composite, i.e. the aluminium matrix and the silicon carbide particles. Measurements were performed along 21 directions and compared to a stress-free reference powder in order to establish the complete residual stress tensor. As shown in Noyan and Cohen (1987) and Hanus and Ericsson (1995b) it is possible to separate the total stress tensor ${ }^{t} \sigma$ in a macrostress ${ }^{M} \sigma$ and a pseudomacrostress ${ }^{\mu} \sigma$ component according to: ${ }^{t} \sigma={ }^{M} \sigma+{ }^{\mu} \sigma$. By definition the macrostress is the average of the measured stress over the diffracting volume and thus is the same for the two phases of the material. The pseudomacrostress are then the deviation of the measured total stress from the macrostress. In the present study only the results related to the macrostress are presented since in the calculations the material is considered as homogeneous and isotropic and therefore the residual stresses obtained with the direct stationary method are macrostresses. A full description of the experimental details and results is given in (Hanus and Ericsson, 1995b).

Concerning the numerical simulations the two-dimensional mesh composed of 265 nodes, shown in Fig. 9, was chosen to describe the groove. The boundary conditions are the following: symmetry across the line $z=0\left(u_{z}=0\right)$, axisymmetry along the axis $r=0$ $\left(u_{\theta}=0\right)$ and prescribed displacements at the nodes pointed by the arrows $\left(u_{r}=0\right)$. As mentioned earlier, the sample is maintained by two secondary rollers, placed just outside the groove, to sustain the load transferred by the main roller. The latter boundary condition is in the present axisymmetrical configuration a good compromise to account for these

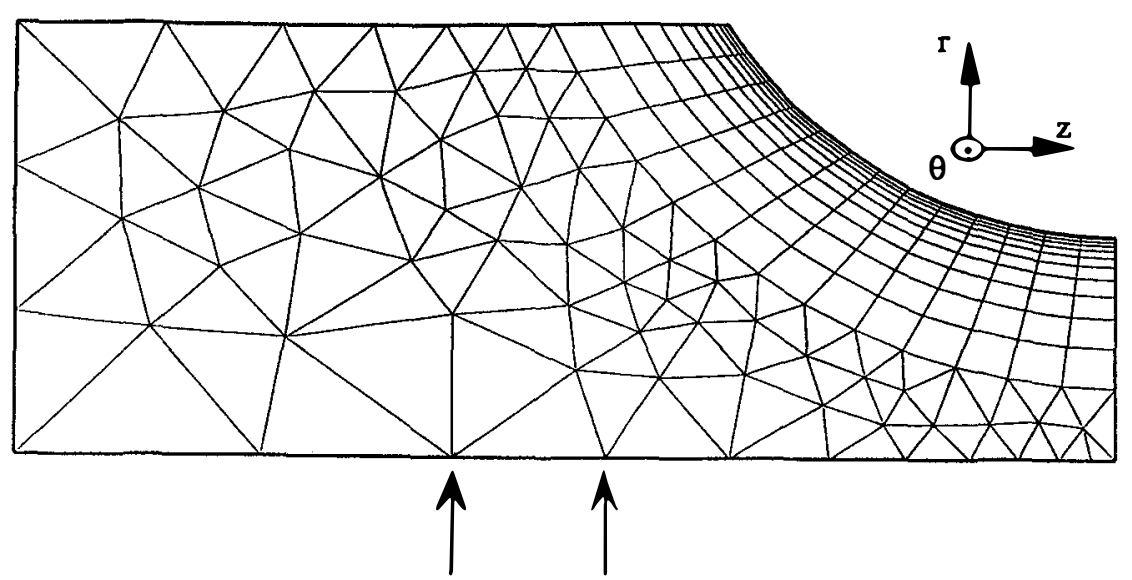

Fig. 9. Two-dimensional mesh of the groove. The arrows indicate where the radial displacement was blocked. 
rollers which allow a limited bending of the groove. This particular boundary condition is however not a sensitive factor: calculations performed with a fixed axis $\left(u_{r}=0\right.$ on $\left.r=0\right)$ have given very similar results.

For the Fourier decomposition of the pressure distribution in the hoop direction 51 modes were employed and 600 angular sections were used to perform the axisymmetrical calculations. With such a number of harmonical modes an error of less than $1 \%$ is achieved on the central pressure value.

By applying the stationary method described in the previous section one gets the mechanical fields at the stabilized state, i.e. during the last pass of the roller at the maximum applied load. The situation is at that point a little different from the one sketched in Fig. 4, where the geometry was planar and thus the mechanical fields far away from the load coincided with the residual mechanical fields. With the present axisymmetrical geometry the points located far away from the load are the ones situated on the opposite section to the load and thus are submitted to a local three point bending generated by the main and the two secondary rollers. To entirely model the pressure rolling treatment it is therefore necessary to consider the unloading from the maximum applied pressure. To estimate the residual stresses and deformations it was chosen to perform the following calculations:

- extract the plastic deformations obtained on the opposite section by the stationary method,

-inject these deformations on all the sections, and

- perform a calculation with initial plastic deformations by using a classical algorithm of plasticity.

It was found that plasticity occurred during the unloading for all configurations of pressure distribution and friction coefficient.

The computation time on HP 700 work stations is typically about 5 hours. Note that the time would have been much smaller if the contact area was not that elongated, requiring a fine discretization in the orthoradial direction (600 sections).

In order to separate the influence of the different parameters, pressure distribution and friction, several combinations were investigated and are illustrated in Fig. 10. It is chosen to plot the results along the $r$-axis at $z=0$ since diffraction measurements were performed only at the center of the groove for different depths. Two distributions of contact pressure were employed : the one obtained with the finite element method described above (FEM) and the hertzian profile corresponding to a rigid roller (HER). The friction was examined through the following configurations: free rolling $(F=0)$ and frictional slip via a Carter profile combined with three slip zones matching the wear lines (HEA). The parameter $\gamma$ defined in Fig. 5 was given the value 0.25 .

A common feature to all numerical results is the penetration depth achieved by pressure rolling which is about $1 \mathrm{~mm}$. This calculated depth agrees very well with the one measured optically (Fig. 3) or by X-ray diffraction (curve 5).

By comparison of curves 1 and 2 one can evaluate the influence of contact conformity. Variations of $20 \%$ in residual stress value are recorded at the subsurface. It is believed that this phenomenon would be more accentuated when analysing the case of two elastic bodies, which could not be treated in the present work.

The introduction of friction, illustrated with curve 3 , clearly shifts the orthoradial surface residual stress towards a lower compressive value. For memory the friction coefficient for curves 3 and 4 was taken equal to 0.1 .

To enable a comparison of the numerical results with experimental data (EXP), plotted on curve 5 , one needs to take into account the layer removal procedure required for the $\mathrm{X}$ ray diffraction measurements of residual stresses in depth. It is indeed obvious that stress relaxation occurs when electropolishing the sample surface. However, the usually adopted correction proposed by Moore and Evans (1958) is not valid in the present study due to the surface stress gradients generated by pressure rolling. Ballard and Constantinescu (1994) recently developed a mathematical formalism allowing the reconstruction of any residual stress field from data measured after layer removal, which led to an explicit inversion formula for the half-space geometry. Unfortunately this explicit method cannot 
a)

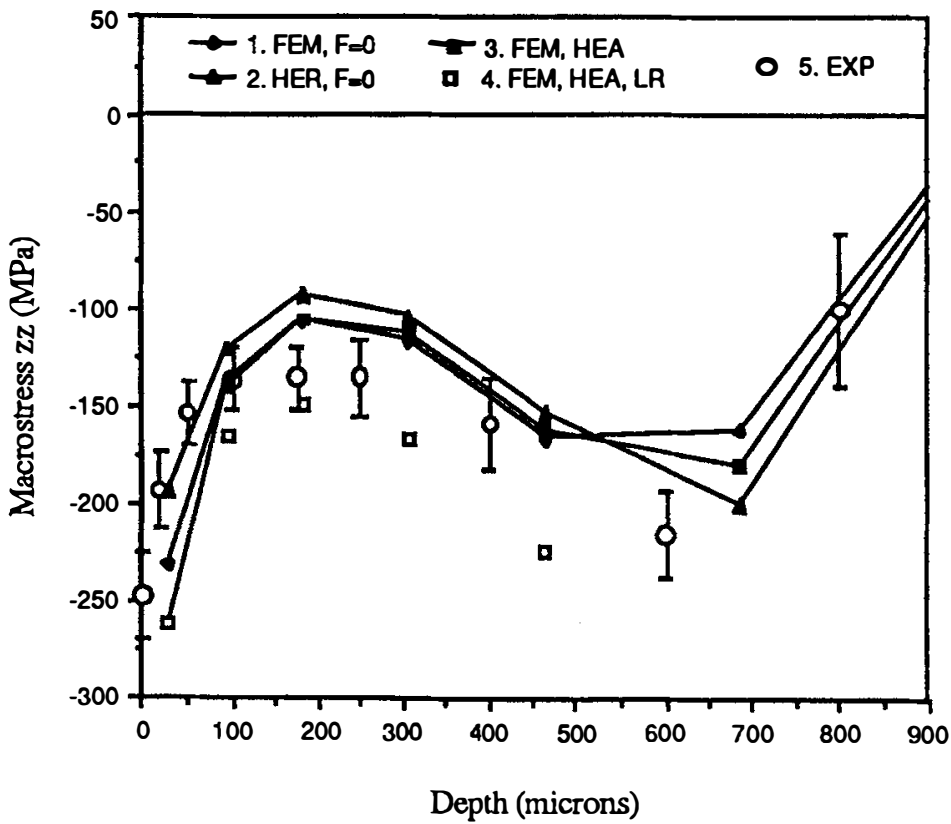

b)

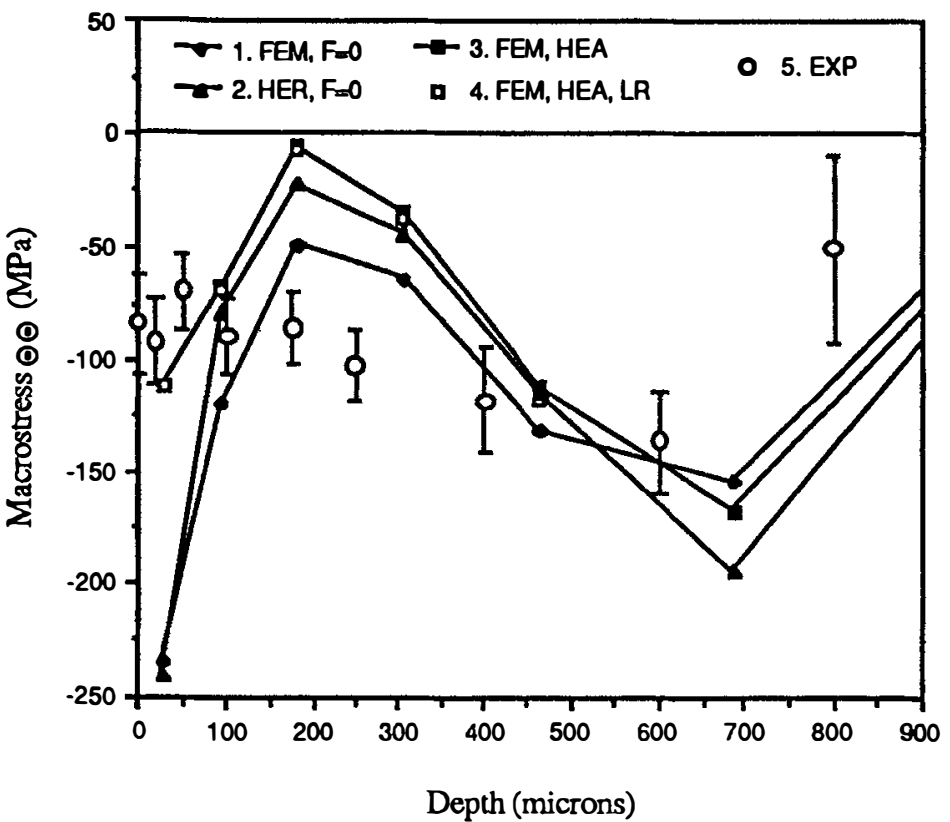

Fig. 10. Residual stress profiles in depth below the center of the groove: (a) along the $z$-axis, (b) in the hoop direction.

be applied due first to the different geometry (the groove cannot be assimilated to an half space) and second to the lack of measurements around the center of the groove. It was therefore chosen to simulate numerically the layer removal (LR) procedure by shifting towards the surface the plastic deformation field and performing at each step an elastic calculation with this initial plastic deformation distribution. This particular modelling leaving the geometry untouched is valid as long as the removed layer is small compared to the thickness of the sample. The changes in stiffness should otherwise be considered. The results after matter removal are shown in curve 4 . The residual stresses in the axial direction $(z$-axis) are clearly more compressive but no difference is observed in the hoop direction. The fact that no correction is to be done in the orthoradial direction can probably be correlated to the absence of stress gradients in that direction. 


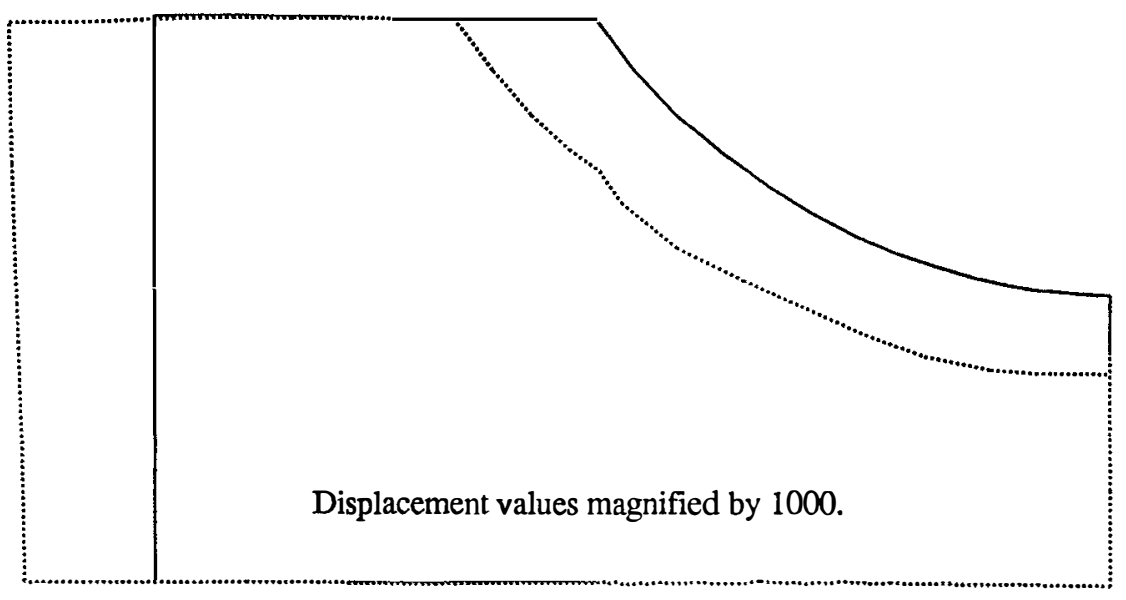

Fig. 11. Plot of the initial (plain line) and deformed (dotted line) geometries.

When confronting the results of curve 4 and the data of curve 5 , one finds that the surface residual stresses are well reproduced by the model and that the shape of the stress profile along the $z$-axis fits very well to the experimental one. Slightly larger compressive stress values are found but they could either be attributed to the elastic compliance of the contact which is not taken into account or to an initial residual stress field induced by quenching. Considering both the roller and the sample elastic would indeed reduce the maximum applied pressure. In the hoop direction a discrepancy between the residual stress profile found with the model and the experience arises in the subsurface. The reason for this misfit may lie in the assumption of isotropy of the material. The samples used in the present study are indeed machined from extruded bars and when examining the microstructure it is observed (Hanus and Ericsson, 1995b) that the ceramic particles of the composite are substantially aligned along the extrusion direction, i.e. the $z$-axis in Fig. 1. This preferred orientation of the particles leads to anisotropy which was not taken into account since the identification of the mechanical parameters was carried out with unidimensional tests performed along the z-axis.

Concerning the little step evidenced in Fig. 3, a plot of the residual displacements generated by pressure rolling gives an alternative explanation to its presence. As shown in Fig. 11 a local variation in normal displacement occurs at the edge of the contact zone. This peak, intrinsic to the present mechanical surface treatment, is about $1 \mu \mathrm{m}$ and therefore too small to fully account for the observed surface mismatch. In consequence it is believed that the step originates from both the pressure rolling and the deformation of the ridges generated during machining (turning).

\section{CONCLUSIONS}

Pressure rolling an aluminium matrix reinforced by ceramic particles with a hard steel roller revealed two important experimental facts:

- the presence of two wear lines separating the contact zone into three regions of opposite microslip. Their origin lies in the difference in peripheral velocity of the two bodies in contact which in turn results from the coupling effect of a large conformity and of the disproportion in size of the roller compared to the sample ;

- the generation of a step at the edge of the rolled zone which can only partially be explained by the residual displacements generated by pressure rolling.

A finite element program has been used to model the conforming contact between a rigid roller and an elastic sample. It was found that the static pressure distribution is no longer elliptical as would be the case with an Hertzian contact. Significative variations from the Hertz theory were observed for the contact dimensions and the central pressure. 
The pressure rolling treatment has been modelled by the means of a direct stationary method giving in fine the mechanical fields at the stabilized state. In order to reduce the complexity of dealing with a three-dimensional elastoplastic problem, a Fourier decomposition of the pressure distribution in the hoop direction was performed reducing thus the mechanical problem to a succession of two-dimensional analyses.

The outputs of the model, namely the residual stresses, have been compared to experimental data issued from residual stress measurements by X-ray diffraction. A good agreement was found for the penetration depth, the surface residual stresses and their profiles in depth.

Acknowledgements-The authors would like to thank Renault S. A. for financial support. E. H. would like to acknowledge Drs Sahbi Braham and Andrei Constantinescu for valuable discussions and assistance with computer programming.

\section{REFERENCES}

Akagaki, T. and Kato, K. (1987). Plastic flow process of surface layers in flow wear under boundary lubricated conditions. Wear 117, 179.

Ballard, P. and Constantinescu, A. (1994). On the inversion of subsurface residual stresses from surface stress measurements. J. Mech. Phys. Solids (to appear).

Barghava, V., Hahn, G. T. and Rubin, C. (1985a). An elastic-plastic finite element model of rolling contact. Part 1 : analysis of single contacts. ASME J. Appl. Mech. 52, 67-74.

Barghava, V., Hahn, G. T. and Rubin, C. (1985b). An elastic-plastic finite element model of rolling contact. Part 2: analysis of repeated contacts. ASME J. Appl. Mech. 52, 75-81.

Barghava, V., Hahn, G. T. and Rubin, C. (1988). Analysis of rolling contact with kinematic hardening for rail steel properties. Wear 122, 267-283.

Benamar, A., Lu, J. and Flavenot, J. F. (1991). Galetage d'un acier inoxydable. CETIM Informations 124, 49-54.

Braham, S. (1991). Modélisation du galetage des vilebrequins. Evolution des contraintes résiduelles sous chargement de service. Thèse de doctorat, Ecole Polytechnique, Palaiseau, France.

Brand, A., Flavenot, J. F., Gregoire, R. and Tournier, C. (1980). Recueil de données technologiques sur la fatigue, CETIM, Senlis, France.

Carter, F. W. (1926). On the action of a locomotive driving wheel. Proc. Roy. Soc. A112, 151.

Dang Van, K. and Maitournam, M. H. (1993). Steady-state flow in classical elastoplasticity: applications to repeated rolling and sliding contact. J. Mech. Phys. Solids 41, 1691-1710.

Flavenot, J. F. and Lu, J. (1988). Comparaison des contraintes résiduelles introduites per grenaillage, martelage et galetage, dans un acier inoxydable. llème Conf. sur le Grenaillage, Senlis, France.

Hanus, E. (1993). Influence of pressure rolling and fatigue on the residual stress state of metal matrix composites. Internal report 779, Linköping Studies in Science and Technology, University of Linköping.

Hanus, E. and Ericsson, T. (1995a). Influence of four point bending fatigue on the residual stress state of a pressure rolled particulate reinforced metal matrix composite. Mat. Sci. Engng A194, 147-156.

Hanus, E. and Ericsson, T. (1995b). Influence of pressure rolling on the residual stress state of a particulate reinforced metal matrix composite. Mat. Sci. Engng A190, 155-163.

Heathcote, H. L. (1921). The ball bearing: in the making, under test and on service. Proc. Institute of Automobile Engineers 15, 569.

Hills, D. A., Nowell, D. and Sackfield, A. (1993). Mechanics of Elastic Contacts, 1st edition. Butterworth Heinemann Ltd.

Johnson, K. L. (1985). Contact Mechanics, Cambridge University Press, Cambridge.

Kapoor, A. and Johnson, K. L. (1994). Plastic ratchetting as a mechanism of metallic wear. Proc. Roy. Soc. A.

Mahnig, F. (1981). Schwing- und Betriebsfestigkeit gegossener Fahrzeugsteile. Schweizer Maschinenmarkt 49.

Maitournam, H. M. and Dang Van, K. (to be published).

Moore, M. G. and Evans, W. P. (1958). Mathematical correlation for stress in removed layers in X-ray diffraction residual stress analysis. SAE Trans. 66, 340-345.

Noyan, I. C. and Cohen, J. B. (1987). Residual Stress: Measurement by Diffraction and Interpretation, SpringerVerlag, Berlin.

Persson, C., Weiland, A. and Johannesson, T. (1993). Elastic and plastic properties of metal matrix composites. Dissertation 328, Linköping Studies in Science and Technology, University of Linköping.

Zarka, J. (1980). Direct analysis of elastic-plastic structures with overlay materials during cyclic loading. Int. J. Num. Meth. Engng 15, 225.

Zarka, J., Frelat, J., Inglebert, G. and Kasmai-Navidi, P. (1988). A New Approach in Inelastic Analysis of Structures. Martinus Nijhoff Pub.

Zienkiewicz, O. C. (1977). Finite Element Method, 3rd edition, McGraw-Hill, New York. 